\title{
Impaired autonomy and rejection of treatment
}

Two important moral principles can, and occasionally do, come into conflict in the context of medical practice: the first is the principle of helping others who are in need (beneficence), presumably the basic moral principle motivating the caring professions; the second is respect for people's autonomy - acknowledgment of their right to make their own deliberated decisions within the context of their own life plan and preferences, so far as this does not harm others. Normally, of course, these two principles do not conflict - people consult doctors because they have medical problems which they want the doctors to do their best to abolish or ameliorate. In a minority of cases, however, the patient rejects the course of action proposed by the doctor and the doctor's dilemma is generated.

The polar cases are relatively uncontroversial. Thus when a patient is clearly competent to make his own decisions and rejects his doctor's advice despite understanding it and the anticipated consequences of rejecting it, then a consensus probably exists in favour of respecting the patient's decision. Hence contemporary medical respect for life-threatening decisions by Jehovah's Witnesses to refuse blood transfusions and by hunger strikers to refuse food and medical attention.

At the other pole, when a patient is clearly incompetent to make autonomous decisions it is widely agreed that beneficent decisions must be taken on his or her behalf, overriding, if this seems desirable, the incompetent patient's protests. A young child is operated on for appendicitis even if he refuses most volubly; a severely mentally handicapped patient is treated with antibiotic injections for his meningitis even if he does hate needles. A patient in a severe confusional state is treated against his will when this is judged necessary. All this is relatively uncontroversial. More controversial is who should make the decisions and on what basis, though once again a consensus is apparently emerging that next of kin and/or the patient's loved ones are presumed to be best placed to make such decisions, in the context of medical advice and where possible on the basis of what the patient would decide autonomously, but failing that, on the basis of the patient's best interests. The presumption that the next of kin should decide on behalf of the incompetent patient is always defeasible and if the doctors or others believe that particular decisions are not what the patient would have autonomously wished or not in the patient's best interests, and if agreement between them and the relatives is impossible it is open to them to obtain a judicial assessment.

What, however, differentiates the patient who is competent to make his own deliberated decisions and thus is to have his autonomy respected from the patient who is not? The symposium in this issue of the journal and the paper in the American fournal of Psychiatry which provoked it (1) analyse this issue of competence (or competency - the final ' $y$ ' is sometimes added where the term has a legal connotation) in the context of 'competent but irrational' refusal of electroconvulsive therapy (ECT) as treatment for depression.

The first important point to emerge from the symposium is that information is essential for autonomous and therefore rational decision-making. One cannot reason or deliberate about alternative courses of action if one has no information about them, and as Dr Taylor, a forensic psychiatrist, points out, patients are likely to make irrational decisions if their doctors give them inadequate information. She explains in detail the clinical importance of ensuring that patients are given adequate information, and given it personally and with care. Nonetheless, as Dr Taylor also points out, the amount of information which patients actually retain is often likely to be fairly limited. How much is necessary for competent decision-making by the patient? Dr Culver and his colleagues recommend a 'minimalist' requirement - a patient should be regarded as competent to reject or accept medical treatment if he knows the doctor believes he is ill and in need of treatment, knows the doctor believes the treatment may help his illness and knows he is expected to decide whether or not to have the treatment. The grounds for this minimalism are that others should not make decisions for patients unless 'it is abundantly clear that the patient is simply unable to represent his or her own interests'.

One problem with this requirement is, as $\mathrm{Dr}$ Taylor points out, that patients may meet the cognitive standards set by Culver et al, manifest impeccable logical reasoning ability, and yet, because of their seriously distorted perception of the world, base much of their reasoning on false premises. If a patient 'knows' that guns are pointing at him wherever he goes it makes 
good sense for him to run away or hit back - and it makes good sense to pity and scorn the doctor for not being able to see the guns, or hear the voices, and for diagnosing him as a paranoid psychotic. But is that sort of reasoning to be regarded as competent? By the minimal criteria of Culver et al presumably it may be; and rejection of medication, however irrational it may be, would therefore be accepted. Many, clinicians and non-clinicians alike, would not accept such decisions as being competently made, nor would they want them respected if they led to actions which harmed others or the patient himself. Thus while Culver et al are surely right - in the interests of respecting patients' autonomy - to insist on a 'minimalist' criterion for competence to reject treatment it seems necessary to allow that if a patient's perception of reality is sufficiently distorted by delusions, illusions and hallucinations, then his competence to reject treatment may properly be questioned even if he meets Culver and his colleagues' criteria.

However, Professor Sherlock is surely right to criticise the Culver criteria on the grounds that they are only cognitive whereas informed consent and rejection require not only adequate information but also what Sherlock calls voluntariness by which he means 'an uncoerced consent'. And Dr Taylor raises similar doubts in relation to common psychiatric conditions in which patients show no sign of being able to make free decisions of any kind: the patient who just does not know what to do; the patient who sits in the corner wringing his hands and saying nothing; the patient who has 'more important things to think about' - all manifest grossly impaired volition (still these days philosophically a fishy concept but an unshakably real phenomenon to most clinicians). Their cognitive status, however, may be well up to the standards required by Culver et al for recognition of competence. Once again it seems sensible to modify their minimalist cognitive criteria by adding a criterion of voluntariness - a requirement that the patient is in a state of mind in which he can make ordinary voluntary decisions.

Here, however, great care is needed - in the interests of justice - to make sure that the criteria for voluntariness required of patients are no more stringent than those required of anyone else in society for his autonomy to be recognised. Sherlock suggests that an irrational refusal to have ECT can in itself be grounds for classifying a patient as incompetent. Somewhat contentiously classifying this as a 'phobia' he says that the patient 'is no more free to decide vis a vis the dreaded object than he would be were he faced with severe hardship for failure to comply with a command to consent'. This doctrine that the presence of a phobia is sufficient for a patient to be judged incompetent to reject treatment has only to be universalised to be shown to be far too demanding. Thus, according to the doctrine, if a patient consults her psychiatrist about an admitted phobia to do with, say, spiders or flying or open spaces, and the doctor confirms the diagnosis he immediately is justified in deeming her incompetent to decide about her treatment (because she has a phobia) and in instituting against her will any standard treatment he happens to favour.

Voluntariness and autonomy can be greatly impaired in ordinary life without a person's right to make his own decisions being overridden; similar minimalist standards should in justice be set for patients. Thus, while recognition should be given to the fact that mental and other illness can on occasion impair the patient's competence to give any sort of voluntary decision (even if he meets the cognitive standards proposed) the mere presence of a psychiatric or other disorder cannot in itself justify an assessment of incompetence to decide on treatment.

Finally, Professor Sherlock's justification of paternalistic intervention to force a depressed patient to have ECT against his will on the grounds that by doing so he would actually be respecting the patient's autonomy by seeking to increase it requires critical consideration. In a recent issue of the journal an editorial criticised Dr Komrad's argument that illness always represented a state of diminished autonomy and that this justified paternalistic medical interventions imposed in order to restore or increase the patient's autonomy by ameliorating the effects of the illness (2). Professor Sherlock's argument is similar. To respect a patient's irrational decision to refuse ECT is, he writes, to respect only a 'limited autonomy' and it is better to override that decision in the interests of restoring the patient's full autonomy. 'If we do value autonomy we ought to pursue it in its fullest possible form, not in the truncated one-dimensional case of refusal of ECT. If autonomy is a good then I submit that the morally appropriate course of action is to foster the autonomy of patients by relieving to the best of our abilities the impediments to autonomy such as major depression'.

There can be no objection to this when the patient consents. But when such 'relief of impediments' is imposed against the competent patient's will, then this benign paternalism represents, as Lesser points out, a serious threat to personal freedom. Autonomy is not an all or nothing phenomenon (3). People are autonomous to different degrees, their autonomy varying with time and circumstances. If mere evidence of impairment of autonomy (or even of serious impairment) is to be used to justify compulsory intervention by others in order to increase people's autonomy then all standard concepts of respect for autonomy and respect for individual liberty will have taken on new, and to many, somewhat sinister meanings.

\section{References and notes}

(1) Culver C M, Ferrell R B, Green R M. ECT and special problems of informed consent. American journal of psychiatry 1980; 137: 5: 586-597.

(2) Anonymous. On paternalism and autonomy (editorial). Fournal of medical ethics 1983; 9: 4.

(3) Benson J. Who is the autonomous man? Philosophy 1983; 58: 223: 5-17. 